\title{
Hepatitis E-Associated Lower Extremity Weakness: Case Report and Review of Literature
}

\author{
Belen Tesfaye ${ }^{\mathrm{a}, \mathrm{b}}$, Firew Wubiee ${ }^{\mathrm{a}}$, Angesom Kibreab ${ }^{\mathrm{a}}$, Rehana Begum ${ }^{\mathrm{a}}$
}

\begin{abstract}
Hepatitis E virus (HEV) infection is a well-known cause of acute hepatitis in developing countries. However, autochthonous (locally acquired) HEV infection is also emerging in industrialized countries. Neurologic signs and symptoms are an emerging extrahepatic manifestation of HEV infection. An association between neurologic manifestations (e.g., Guillain-Barre syndrome, neuralgic amyotrophy, and acute transverse myelitis) and acute HEV infection has been suggested. We present a case of a 26-year-old Hispanic female who presented with lower extremity weakness and elevated liver enzymes who was found to be positive for hepatitis E IgM antibodies. We recommend that clinicians strongly consider the possibility of HEV infection in patients with neurologic disorders, especially those with peripheral nerve involvement and liver abnormalities indicated by blood tests. Patients with unexplained hepatitis should be tested for hepatitis E, whatever their age or travel history.
\end{abstract}

Keywords: Hepatitis E; Weakness; Neurology

\section{Introduction}

Hepatitis E virus (HEV) infection is a well-known cause of acute hepatitis in developing countries. However, autochthonous (locally acquired) HEV infection is also emerging in industrialized countries, where it is caused by HEV genotype 3 and thought to be a zoonosis transmitted by pigs $[1,2]$. Within the past few years, HEV has been responsible for chronic hepatitis, which can rapidly evolve to cirrhosis, in immunocompromised patients [3-8]. However, little data regarding HEV-related extrahepatic manifestations have been published, although an association between neurologic manifestations (e.g., Guillain-Barre syndrome, neuralgic amyotrophy, and

Manuscript accepted for publication July 04, 2014

aHoward University Hospital, Washington DC, USA

${ }^{b}$ Corresponding Author: Belen Tesfaye, Howard University Hospital, 2041

Georgia Avenue, Washington DC, USA. Email: belenaye@yahoo.com

doi: http://dx.doi.org/10.14740/jmc1843w acute transverse myelitis) and acute HEV infection has been suggested [9-13].

The association between neurologic signs and symptoms and HEV infection has been based on detection of anti-HEV immunoglobulin (Ig) M in serum. However, Rianthavorn et al reported a case of HEV genotype 3-induced neuralgic amyotrophy in which HEV RNA was detected in the serum of patients with neurologic signs and symptoms [14].

\section{Case Report}

A 26-year-old Hispanic female with a history of alcohol abuse sought care for progressive lower extremity weakness. She has been working in a restaurant, had not traveled outside the US within the last 5 years and had had no history of contact with pigs. On Physical examination power was $3 / 5$ on bilateral lower extremities with intact sensation and normal urinary and bowel control.

CSF analysis detected no abnormality. Magnetic resonance imaging (MRI) of the head, cervical, thoracic and lumbar spine showed no abnormalities. Liver function tests showed elevated alanine aminotransferase (ALT) 125 IU/L (reference 3 - 35 IU/L), aspartate amino transferase (AST) 902 IU/L (reference 3 - 35 IU/L), alkaline phosphatase 191 IU/L (reference 3 - 35 $\mathrm{IU} / \mathrm{L}$ ), total bilirubin $1.5 \mathrm{mg} / \mathrm{dL}$, and GGT $744 \mathrm{IU} / \mathrm{L}$ (reference 3 - 35 IU/L). Anti-HEV IgM was detected in the serum. Serology was negative for CMV DNA, EBV DNA, toxoplasma IgG, HSV 1 and 2. Hepatitis A, B and C, alpha 1 antitripsin, ceruloplasmin, and vitamin B12 levels were normal. Abdominal ultrasound showed enlarged liver with diffusely increased echogenicity without focal mass. Percutaneous live biopsy showed grade 2, stage 2 steatohepatitis (Brunt system).

The patient was managed conservatively and no specific treatment was given; neurologic signs and symptoms improved within 3 months, and laboratory parameters returned to reference range within 2 months.

\section{Discussion}

Data about neurologic sequelae of HEV infection are scarce. In industrialized countries, autochthonous HEV infection has been described in persons who have not traveled to areas 
where HEV has traditionally been considered endemic (mostly non industrialized countries) [1]. Hepatitis E for these persons is thought to be a porcine zoonosis and is generally caused by HEV genotype 3 (and genotype 4 in China and Japan). The clinical features of hepatitis $\mathrm{E}$ in persons in industrialized countries are quite distinct from those in developing countries: HEV occurs most often in middle-aged and elderly men, and associated mortality rate is $5-10 \%$ [1]. Information about the spectrum and magnitude of disease caused by HEV genotype 3 is still emerging. For example, in recent years chronic HEV infection (with rapid development of cirrhosis) in immunocompromised persons has been demonstrated [3-8].

The mechanism of neurologic damage in our patient is unknown. Many viruses (including hepatotropic viruses) trigger neurologic signs and symptoms, especially Guillain-Barre syndrome [15]. Such infections may elicit an immune response that cross-reacts with axolemmal or Schwann cell antigens and thereby damages peripheral nerves [15]. Neurologic signs and symptoms may result from infection with, or emergence of, neurotropic $\mathrm{HEV}$ variants [16].

\section{Conclusion}

In conclusion, neurologic signs and symptoms are an emerging extrahepatic manifestation of HEV genotype 3 infection. We recommend that clinicians strongly consider the possibility of $\mathrm{HEV}$ infection in patients with neurologic disorders, especially those with peripheral nerve involvement and liver abnormalities indicated by blood tests.

Patients with unexplained hepatitis should be tested for hepatitis E, whatever their age or travel history. The diagnosis may be suggested by HEV serology but should be confirmed by molecular documentation of HEV RNA in the serum, CSF, or both.

\section{References}

1. Dalton HR, Bendall R, Ijaz S, Banks M. Hepatitis E: an emerging infection in developed countries. Lancet Infect Dis. 2008;8(11):698-709.

2. Dalton HR, Stableforth W, Thurairajah P, Hazeldine S, Remnarace R, Usama W, Farrington L, et al. Autochthonous hepatitis E in Southwest England: natural history, complications and seasonal variation, and hepatitis E virus IgG seroprevalence in blood donors, the elderly and patients with chronic liver disease. Eur J Gastroenterol Hepatol. 2008;20(8):784-790.

3. Kamar N, Selves J, Mansuy JM, Ouezzani L, Peron JM,
Guitard J, Cointault O, et al. Hepatitis E virus and chronic hepatitis in organ-transplant recipients. N Engl J Med. 2008;358(8):811-817.

4. Ollier L, Tieulie N, Sanderson F, Heudier P, Giordanengo V, Fuzibet JG, Nicand E. Chronic hepatitis after hepatitis E virus infection in a patient with non-Hodgkin lymphoma taking rituximab. Ann Intern Med. 2009;150(6):430431.

5. Dalton HR, Bendall RP, Keane FE, Tedder RS, Ijaz S. Persistent carriage of hepatitis $\mathrm{E}$ virus in patients with HIV infection. N Engl J Med. 2009;361(10):1025-1027.

6. Gerolami R, Moal V, Colson P. Chronic hepatitis E with cirrhosis in a kidney-transplant recipient. N Engl J Med. 2008;358(8):859-860.

7. Kamar N, Mansuy JM, Cointault O, Selves J, Abravanel F, Danjoux M, Otal P, et al. Hepatitis E virus-related cirrhosis in kidney- and kidney-pancreas-transplant recipients. Am J Transplant. 2008;8(8):1744-1748.

8. Haagsma EB, van den Berg AP, Porte RJ, Benne CA, Vennema H, Reimerink JH, Koopmans MP. Chronic hepatitis $\mathrm{E}$ virus infection in liver transplant recipients. Liver Transpl. 2008;14(4):547-553.

9. Kamani P, Baijal R, Amarapurkar D, Gupte P, Patel N, Kumar P, Agal S. Guillain-Barre syndrome associated with acute hepatitis E. Indian J Gastroenterol. 2005;24(5):216.

10. Sood A, Midha V, Sood N. Guillain-Barre syndrome with acute hepatitis E. Am J Gastroenterol. 2000;95(12):36673668.

11. Loly JP, Rikir E, Seivert M, Legros E, Defrance P, Belaiche J, Moonen G, et al. Guillain-Barre syndrome following hepatitis E. World J Gastroenterol. 2009;15(13):16451647.

12. Fong F, Illahi M. Neuralgic amyotrophy associated with hepatitis E virus. Clin Neurol Neurosurg. 2009;111(2):193-195.

13. Mandal K, Chopra N. Acute transverse myelitis following hepatitis E virus infection. Indian Pediatr. 2006;43(4):365366.

14. Rianthavorn P, Thongmee C, Limpaphayom N, Komolmit P, Theamboonlers A, Poovorawan Y. The entire genome sequence of hepatitis $\mathrm{E}$ virus genotype 3 isolated from a patient with neuralgic amyotrophy. Scand J Infect Dis. 2010;42(5):395-400.

15. Hughes RA, Cornblath DR. Guillain-Barre syndrome. Lancet. 2005;366(9497):1653-1666.

16. Kamar N, Izopet J, Cintas P, Garrouste C, Uro-Coste E, Cointault O, Rostaing L. Hepatitis E virus-induced neurological symptoms in a kidney-transplant patient with chronic hepatitis. Am J Transplant. 2010;10(5):13211324. 